\title{
Effect of different diameters and rake angles of Forstner bit on the quality of drilling on treated oil palm wood
}

\begin{abstract}
Drilling characteristics and quality of oil palm wood (OPW) for high grade furniture manufacturing were determined. The effects of diameter and rake angle of a Fortsner bit on the quality of drilling in treated OPW was investigated in comparison with untreated OPW and rubberwood. Boring qualities of treated OPW proved to be superior to untreated OPW but fell a bit below the quality shown by rubberwood. The $25 \mathrm{~mm}$ diameter bit outperformed the $32 \mathrm{~mm}$ diameter bit, while $30^{\circ}$ rake angle outperformed $20^{\circ}$ rake angle. Treated OPW and rubberwood are of the same class of surface quality with Ra value of 8.65 and $8.63 \mu \mathrm{m}$, respectively, while the untreated OPW is far inferior $(14.28 \mu \mathrm{m})$. In conclusion, the treated OPW shows immense improvement in drilling quality compared to untreated OPW.
\end{abstract}

Keyword: Forstner; Drilling characteristic; Driling quality; Oil palm wood 